Article

\title{
The Impact of Climate Change on the Duration and Division of Flood Season in the Fenhe River Basin, China
}

\author{
Hejia Wang ${ }^{1,2}$, Weihua Xiao ${ }^{2, *}$, Jianhua Wang ${ }^{2, *}$, Yicheng Wang ${ }^{2}$, Ya Huang ${ }^{2,3}$, Baodeng Hou ${ }^{2}$ \\ and Chuiyu $\mathrm{Lu}^{2}$ \\ 1 Department of Hydraulic Engineering, Tsinghua University, Haidian District, Beijing 100084, China; \\ sxjcwhj@126.com \\ 2 State Key Laboratory of Simulation and Regulation of Water Cycle in River Basin, China Institute of Water \\ Resources and Hydropower Research, 1-A Fuxing Road, Haidian District, Beijing 100038, China; \\ wangych@iwhr.com (Y.W.); hygccw@163.com (Y.H.); houbaodeng@163.com (B.H.); cylu@iwhr.com (C.L.) \\ 3 College of Civil Engineering and Architecture, Guangxi University, Nanning 530004, China \\ * Correspondence: jhwangiwhr@126.com (J.W.); xwsen998@163.com (W.X.); Tel.: +86-10-6878-1950 (W.X.) \\ Academic Editor: Yingkui Li \\ Received: 6 January 2016; Accepted: 11 March 2016; Published: 16 March 2016
}

\begin{abstract}
This study analyzes the duration and division of the flood season in the Fenhe River Basin over the period of 1957-2014 based on daily precipitation data collected from 14 meteorological stations. The Mann-Kendall detection, the multiscale moving $t$-test, and the Fisher optimal partition methods are used to evaluate the impact of climate change on flood season duration and division. The results show that the duration of the flood season has extended in 1975-2014 compared to that in 1957-1974. Specifically, the onset date of the flood season has advanced 15 days, whereas the retreat date of the flood season remains almost the same. The flood season of the Fenhe River Basin can be divided into three stages, and the variations in the onset and retreat dates of each stage are also examined. Corresponding measures are also proposed to better utilize the flood resources to adapt to the flood season variations.
\end{abstract}

Keywords: flood season division; flood limit level; climate change; precipitation; Fenhe River Basin

\section{Introduction}

Global climate change is inevitable [1], causing frequently occurring extreme weather and climate events and unevenly distributed rainfall. Fenhe River, the second largest tributary of the Yellow River in Northern China, is experiencing such changes. According to historical records, it had a 5-year-long wet season from 1963 to 1967, and had a 15-year-long dry season from 1979 to 1993. It has been suggested that the climate, especially precipitation, in the Fenhe River Basin has been affected by human activities and natural phenomena such as El Niño-Southern Oscillation and Pacific Decadal Oscillation [2]. Therefore, it is of critical importance to study the variation in the flood season and evaluate the impact of climate change.

Several studies have investigated the duration of flood seasons. Odekunle [3] and Sâmia et al. [4] determined the onset and retreat time of the flood seasons in Nigeria and South American monsoon areas, respectively, and both of their methods were effective. Hachigonta et al. [5] found that the onset date of the flood season in Zambia has a significant spatial variation. Other studies [6-10] have analyzed temporal variations in flood seasons. All of these studies indicate that the onset and retreat time of the flood season have fluctuations that are affected by natural variations over long periods.

Although numerous researchers have investigated the onset and retreat times of the flood season, few studies explore the variation of the flood season in light of climate change. In this paper, we detect 
the abrupt changing point of the climate based on the annual precipitation in 1957-2014 in the Fenhe River Basin, estimate the onset and retreat time of flood seasons divided by this abrupt changing point, and, finally, divide the flood season into three stages to analyze the temporal variation of each stage. Based on the results, we propose measures to alleviate the discord between flood control and flood resources utilization.

\section{Study Area}

The Fenhe River is the largest river in the province of Shanxi, China and also the second largest tributary of the Yellow River. The Fenhe River Basin covers an area of $39471 \mathrm{~km}^{2}\left(110^{\circ} 30^{\prime}-113^{\circ} 32^{\prime} \mathrm{E}\right.$; $\left.35^{\circ} 20^{\prime}-39^{\circ} 00^{\prime} \mathrm{N}\right)$, accounting for $25.3 \%$ of the area of Shanxi. The Fenhe River Basin lies between Mt. Lvliang and Mt. Taihang and irregularly distributed as a wide stripe in West-Central Shanxi. It is located in the mid-latitude continental monsoon climate zone with arid and semiarid climates. During 1957-2014, the mean annual precipitation was $472.4 \mathrm{~mm}$. The drainage map of the Fenhe River Basin is shown in Figure 1.

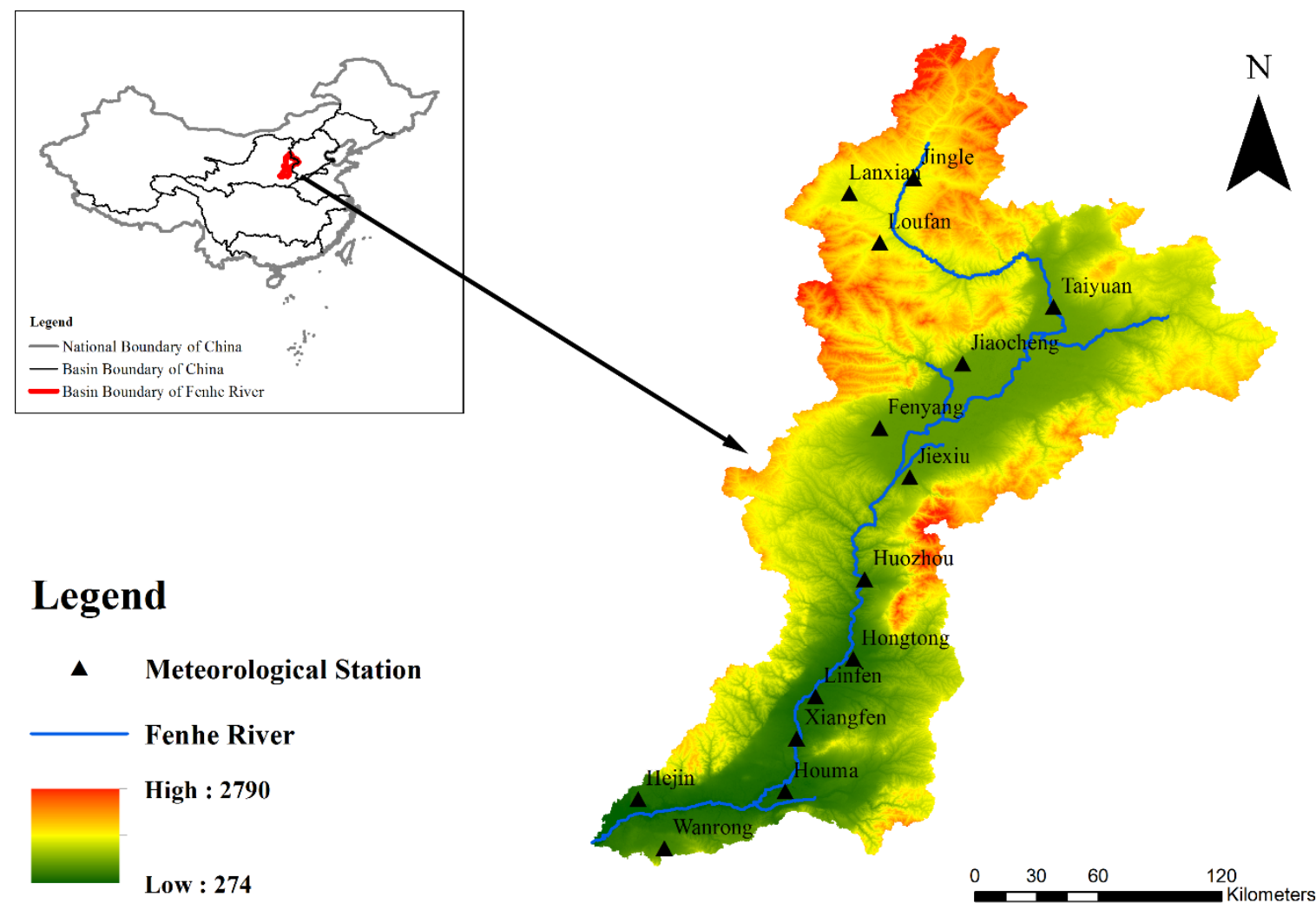

Figure 1. Plane graph of the Fenhe River Basin.

The data used for this study include daily precipitation data from 1957 to 2014 at 14 meteorological stations within the basin, and are obtained from the China Meteorological Administration [11]. Some stations have incomplete and false data records for some years. We use the inverse distance weighted method to fill and replace these missing or false data. It should be stated that the precipitation data during 1957-1979 are separated by rain and snow, but they are no longer separated and have not been since 1980. In this study, the snow data before 1980 are converted to the corresponding rainfall. 


\section{Materials and Methods}

\subsection{Climate Abrupt Change Detection}

Mann-Kendall detection is a nonparametric statistical test method which is widely used in time series data trend tests [12]. Samples are not needed to obey a certain distribution in this way, which is also unacted on the interference of a few outliers. Therefore, it is suitable for hydrology, meteorology, and other non-normal distribution data. In this paper, the annual precipitation during 1957-2014 are chosen as the time series data to detect the abrupt point. The specific steps of Mann-Kendall detection are then further explored [13].

\subsection{The Onset and Retreat Dates of Flood Season}

Currently, the onset and retreat time of flood season are mostly defined by experience, which is inevitably subjective. The accurate detect of the two dates will provide scientific support to relevant sectors to forecast the flood season and to regulate the reservoirs for the purpose of flood control. The moving $t$-test is suitable for the multiscale detection of the change of flood season; the beginning of flood season is a symbol that the precipitation varies from less to more, at which time the abrupt point may exist. The situation is just the opposite when it comes to the end of flood season. Fraedrich et al. took the historical flood level of the River Nile, for example, and found three distinct epochs from AD 622 to AD 1470 [14]. Wang et al. detected the beginning and ending dates of rainy season in Dalian from 1951 to 1998 by applying the moving $t$-test method, which showed that it is more objective and exact than the empirical method [15]. Jiang et al. redistricted the coherently dry/wet episode of the Nile River and found the results were coincided with the historical disaster and famine of Egypt [16]. Other researchers also obtained ideal results by using this method [17-19]. Therefore, the multiscale moving $t$-test is applied in this paper to define the onset and retreat dates of flood season.

The multiscale moving $t$-test is used to detect the differences between two subsamples before and after the abrupt point with equivalent sample sizes, namely, $n=n_{1}=n_{2}$. The $t$-statistic of precipitation in the Fenhe River Basin can be calculated as follows:

$$
t(n, i)=\left(\bar{x}_{i 2}-\bar{x}_{i 1}\right) n^{1 / 2}\left(s_{i 2}^{2}+s_{i 1}^{2}\right)^{-1 / 2}
$$

where

$$
\begin{aligned}
& \bar{x}_{i 1}=\sum_{j=i-n}^{i-1} x_{j} / n ; s_{i 1}^{2}=\sum_{j=i-n}^{i-1}\left(x_{j}-\bar{x}_{i 1}\right)^{2} /(n-1) \\
& \bar{x}_{i 2}=\sum_{j=i}^{j+n-1} x_{j} / n ; s_{i 2}^{2}=\sum_{j=i}^{i+n-1}\left(x_{j}-\bar{x}_{i 2}\right)^{2} /(n-1)
\end{aligned}
$$

The test of the multiscale abruption is realized by altering the $n$ value. $N=2,3, \ldots,<N / 2$, and $i=$ $n+1, \mathrm{n}+2, \ldots, N-n$, where $N$ is the number of days in a year (365 or 366), and $n$ is the timescale. The confidence level of $t$-test at 0.01 is approximately equivalent to the confidence level of Yamamoto and the Mann-Kendall test at 0.05 . In order to make the graphics visualized and the analysis convenient, the further calculation is as follows:

$$
t_{r}(n, i)=t(n, i) / t_{0.01}(n)
$$

$\operatorname{tr}(n, i)$ can be treated as the threshold to judge whether there is an abrupt point. When $\operatorname{tr}(n, i)$ is greater than 1.0, it means that the abruption of variation trend is rising; when $\operatorname{tr}(n, i)$ is less than -1.0 , it means the abruption of variation trend is descending. The center of extreme values of the $\operatorname{tr}(n, i)$ absolute value means that the abruption is the most prominent when the time is $i$ and the timescale is $n$. 


\subsection{Flood Season Division}

Flood season division means dividing the flood season into several stages in the light of the distinct differences and the regularity of flood characteristics during the different periods. Accurate division is the prerequisite for controlling the flood limit level, which can bring huge benefits to agricultural irrigation, power generation, etc., and alleviate the contradiction between flood control and flood resources utilization. Extensive researches on flood season division are conducted, and a mass of methods has been applied to flood season division. Liu et al. successfully divided the flood season in the Geheyan Reservoir by means of the changing point method [20]. Jin et al. used the fuzzy set analysis method with the city of Nanping and divided the flood season into three stages [21]. Many other methods are also ideal for solving this problem [22-27].

The essence of flood season division is a multidimensional orderly clustering analysis of time series. The Fisher optimal partition method is just a method of clustering of ordered samples and was used to divide seismicity period successfully by He et al. [28]. It has some basic characteristics: firstly, it can take multi-index into consideration; secondly, it can meet the time sequence of the flood season; finally, it can confirm the optimum number of flood season divisions. Therefore, the Fisher optimal partition method is applied in this paper to divide the flood season of the Fenhe River Basin.

We can define $\left\{x_{1}, x_{2}, \ldots, x_{n}\right\}$ as ordered samples, where every sample is $m$-dimensional vector. The symbol $B(n, k)$ indicates that $n$ ordered samples are divided into $k$ parts. The division can be expressed as follows:

$$
P_{1}=\left\{i_{1}, i_{1}+1, \ldots, i_{2}-1\right\} ; P_{2}=\left\{i_{2}, i_{2}+1, \ldots, i_{3}-1\right\} ; \ldots P_{k}=\left\{i_{k}, i_{k}+1, \ldots, n\right\},
$$

where division points are $1=i_{1}<i_{2}<\ldots<i_{k}<n=i_{k+1}-1$.

Supposing a part $P$ contains samples $\left\{x_{i}, x_{i+1}, \ldots, x_{j}\right\}$, the mean value can be denoted as follows:

$$
\overline{x_{p}}=\frac{1}{j-i+1} \sum_{t=1}^{j} x_{t}
$$

Therefore, the sum of the squares of deviations of the part can be denoted as follows:

$$
D(i, j)=\sum_{t=i}^{j}\left(x_{t}-\overline{x_{p}}\right)^{T}\left(x_{t}-\overline{x_{p}}\right)
$$

The purpose of the Fisher optimal partition method is to find division points, which make the sum of the squares of deviations of every part the minimum. Consequently, the optimal division can be depicted as the following formula:

$$
B(n, k)=\min \sum_{t=1}^{k} D\left(i_{t}, i_{t+1}-1\right)
$$

The theorem says that the optimal division $B(n, k)$ must be equal to the optimal division $B(n-1, k-1)$ plus the remaining part. According to the theorem above, the optimal division $B(n, 2)$ can be denoted as follows:

$$
B(n, 2)=\min _{2 \leqslant i \leqslant n}\{D(1, i-1)+D(i, n)\}
$$

Similarly, the optimal division $B(n, k)$ can be denoted as follows:

$$
B(n, k)=\min _{2 \leqslant i \leqslant n}\{B(i-1, k-1)+D(i, n)\}
$$


Then, we can obtain the optimal solution by finding the division points in descending order. The division point $i_{k}$ must meet the requirement of the following equation:

$$
B(n, k)=\left\{B\left(i_{k}-1, k-1\right)+D\left(i_{k}, n\right)\right\}
$$

Then, the part $k$ can be obtained: $P_{k}=\left\{i_{k}, i_{k}+1, \ldots, n\right\}$. Similarly, the remaining parts $P_{k-1}, P_{k-2}, \ldots$, $P_{2}, P_{1}$ can be obtained successively.

In this process, we need to draw the $B(n, k)-k$ curve according to the results, and then calculate the absolute value of slope of every division point $f(k)$. Next, the $f(k)-k$ curve can be drawn-if $f(k)$ is greater, the division into $k$ parts is better than $k-1$ parts. When $f(k)$ is close to zero, there is no need for division. Generally, $k$ is the optimal division number of parts when $f(k)$ meets the maximum, and the corner of $B(n, k)-k$ curve is also seen as the optimal division point.

\section{Results}

\subsection{The Detection of Climate Abrupt Point}

Figure 2 displays the results of Mann-Kendall detection of annual precipitation during 1957-2014. Here, $U F(K)$ and $U B(K)$ are statistics sequence which obey standard normal distribution. A intersection exists between $U F(K)$ line and $U B(K)$ line, and it just lies between the two critical lines whose confidence level are 0.05 . The corresponding time of the intersection is 1974 . Therefore, we can divide the period 1957-2014 into two periods, namely, 1957-1974 and 1975-2014. The annual precipitation is on the rise during the former period, while the trend declines during the latter period.

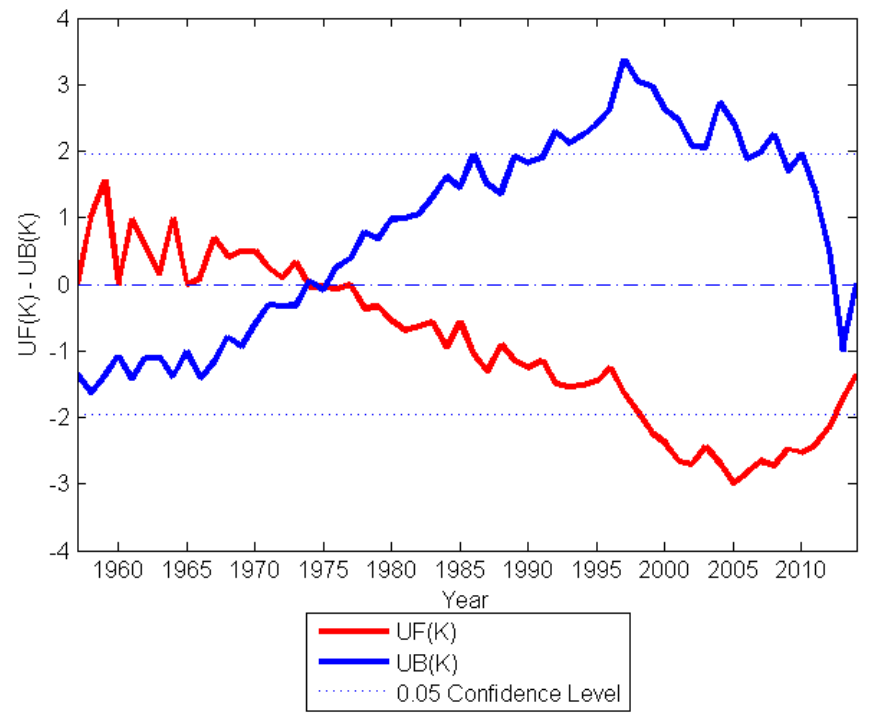

Figure 2. Mann-Kendall detection of the precipitation in the Fenhe River Basin for the period 1957-2014.

\subsection{The Onset and Retreat Dates of Flood Season}

Taking the year 1979 as an example, the result of the multiscale moving $t$-test of the Fenhe River Basin precipitation is shown in Figure 3. The color scale of the contour map shows that the larger the value, the deeper the color. The maximum value of $\operatorname{tr}(n, i)$ is 2.2 , which is greater than 1.0. The corresponding day is 165 and the corresponding timescale is 65 days. It means that the onset date of flood season in 1979 is Day 165, on which the abruption is the most conspicuous in the timescale of 65 days. Similarly, the retreat date of flood season in 1979 is Day 255, on which the abruption is the most conspicuous in the timescale of 63 days. Figure 4 shows the variation trend during 1957-2014, the red line represents the onset date of flood season in the Fenhe River Basin, and the blue line indicates the retreat date. Consequently, the annual average flood season of the two period 1957-1974 and 
1975-2014 can be obtained. The onset and retreat dates of flood season during 1957-1974 are 170 and 253, respectively, and the flood season lasts 84 days long. In a similar way, the onset and retreat dates of flood season during 1975-2014 are 156 and 252, respectively, and the flood season is 13 days longer than that during 1957-1974. Out of convenience with respect to the flood season division, it was necessary to transform the timescale from day to pentad. According to the traditional Chinese calendar, a pentad is 5 days; one year contains 72 pentads. For instance, Day 170 can be converted to 4 June, which means the fourth pentad in June. Therefore, the flood season of 1957-1974 and 1975-2014 are 4 June-2 September and 1 June-2 September, respectively.

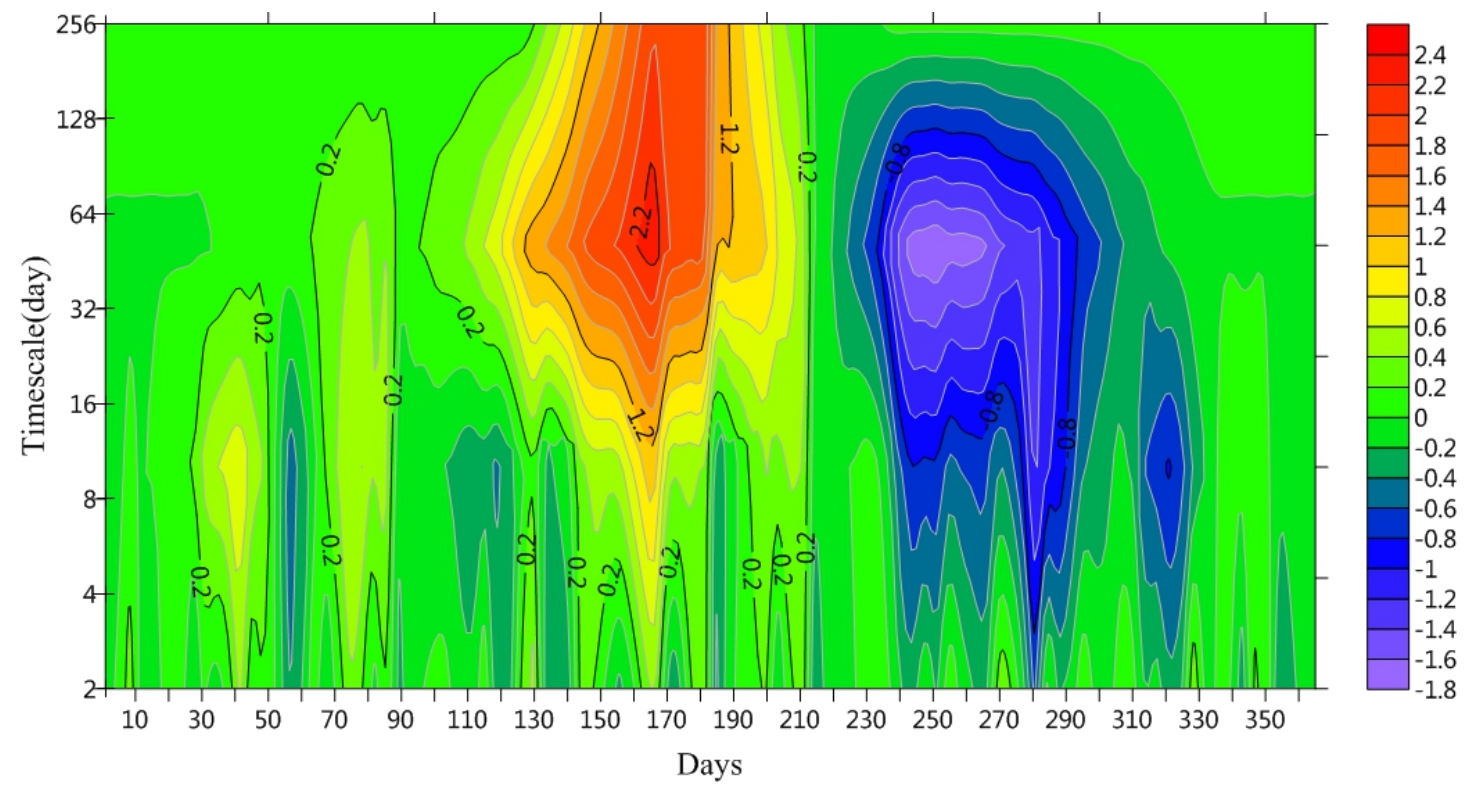

Figure 3. The multiscale moving $t$-test on the Fenhe River Basin daily mean precipitation in 1979.

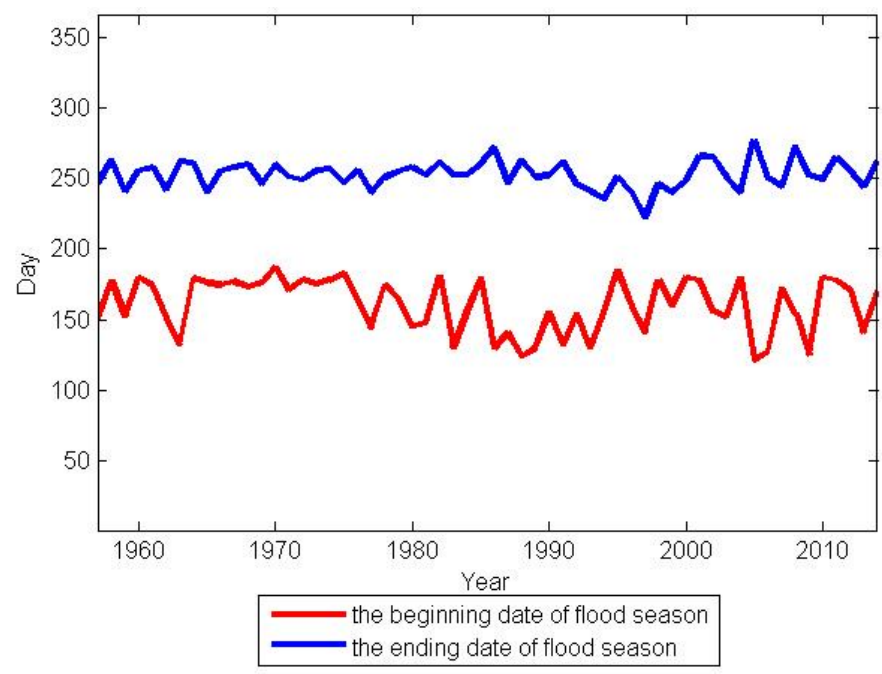

Figure 4. The onset and retreat dates of flood seasons for the period 1957-2014.

\subsection{Flood Season Division}

Five factors that can represent the seasonal rules of precipitation and flood are chosen as basic elements for flood season division: mean pentad precipitation, mean coefficient of variation of pentad precipitation, mean maximum 1-day-precipitation within a pentad, mean maximum 3-day-precipitation within a pentad, and number of hard rain days within a pentad. Tables 1 and 2 
display the result of division of 1957-1974 and 1975-2014, respectively. Figure 5 shows the $B(n, k)-k$ curve and $f(k)-k$ curve of 1957-1974 and 1975-2014, respectively. The $f(k)$ is the maximum when $k$ is equal to 3 in picture $(b)$, and the curve $B(n, k)-k$ has a turning at the same time. Therefore, the optimal division number $k$ is 3 during 1957-1974, which means the flood season can be divided into three stages during 1957-1974, namely, pre-flood season, main flood season, and post-flood season. The corresponding classification in Table 2 is $1-3,4-9,10-17$, which means the pre-flood season is from 4 June to 6 June, the main flood season is from 1 July to 6 July, and the post-flood season is from 1 August to 2 September. Analogously, the flood season can be divided into three stages during 1975-2014. To be specific, the pre-flood season is from 1 July to 6 July, the main flood season is from 1 July to 6 August, and the post-flood season is from 1 September to 2 September. Figure 6 shows the length of each stage. By contrast, we can see the pre-flood season is 15 days in advance; thus, it lasts 15 days longer than before, the main flood season lasts 30 days longer than before, and the post-flood season is 30 days less, accordingly.

Table 1. Result of flood season division of the Fenhe River Basin during 1957-1974.

\begin{tabular}{cccc}
\hline $\mathbf{k}$ & $\mathbf{B}(\mathbf{n}, \mathbf{k})$ & $\mathbf{f ( k )}$ & Classification \\
\hline 2 & 0.742 & & $1-2,3-17$ \\
3 & 0.223 & 0.519 & $1-3,4-9,10-17$ \\
4 & 0.091 & 0.132 & $1-2,3-4,5-9,10-17$ \\
5 & 0.072 & 0.019 & $1-2,3-4,5-7,8-9,10-17$ \\
6 & 0.052 & 0.02 & $1-2,3-4,5-7,8,9,10-17$ \\
7 & 0.036 & 0.016 & $1-2,3,4,5-7,8,9,10-17$ \\
8 & 0.025 & 0.011 & $1-2,3,4,5,6-7,8,9,10-17$ \\
9 & 0.016 & 0.009 & $1-2,3,4,5,6-7,8,9,10,11-17$ \\
10 & 0.01 & 0.006 & $1-2,3,4,5,6,7,8,9,10,11-17$ \\
11 & 0.007 & 0.003 & $1-2,3,4,5,6,7,8,9,10,11-14,15-17$ \\
12 & 0.004 & 0.003 & $1-2,3,4,5,6,7,8,9,10,11-13,14,15-17$ \\
13 & 0.002 & 0.002 & $1-2,3,4,5,6,7,8,9,10,11-13,14,15-16,17$ \\
14 & 0 & 0.002 & $1-2,3,4,5,6,7,8,9,10,11-12,13,14,15-16,17$ \\
15 & 0 & 0 & $1,2,3,4,5,6,7,8,9,10,11-12,13,14,15-16,17$ \\
16 & 0 & 0 & $1,2,3,4,5,6,7,8,9,10,11,12,13,14,15-16,17$ \\
\hline
\end{tabular}

Table 2. Result of flood season division of the Fenhe River Basin during 1975-2014.

\begin{tabular}{cccc}
\hline $\mathbf{k}$ & $\mathbf{B}(\mathbf{n}, \mathbf{k})$ & $\mathbf{f ( k )}$ & Classification \\
\hline 2 & 1.021 & & $1-6,7-20$ \\
3 & 0.437 & 0.584 & $1-6,7-18,19-20$ \\
4 & 0.263 & 0.174 & $1-6,7-11,12,13-20$ \\
5 & 0.192 & 0.071 & $1-6,7-11,12,13-18,19-20$ \\
6 & 0.146 & 0.046 & $1-6,7-8,9-11,12,13-18,19-20$ \\
7 & 0.103 & 0.043 & $1-4,5-6,7-8,9-11,12,13-18,19-20$ \\
8 & 0.062 & 0.041 & $1-4,5-6,7-8,9-11,12,13-17,18,19-20$ \\
9 & 0.025 & 0.037 & $1-4,5-6,7-8,9-8,9-11,12,13-16,17,18,19-20$ \\
10 & 0.021 & 0.004 & $1-4,5-6,7-8,9-11,12,13,14,15-16,17,18,19-20$ \\
11 & 0.013 & 0.008 & $1-4,5-6,7-8,9-10,11,12,13,14,15-16,17,18,19-20$ \\
12 & 0.01 & 0.003 & $1-2,3-4,5-6,7-8,9-10,11,12,13,14,15-16,17,18,19-20$ \\
13 & 0.007 & 0.003 & $1-2,3,4,5-6,7-8,9-10,11,12,13,14,15-16,17,18,19-20$ \\
14 & 0.005 & 0.002 & $1-2,3,4,5-6,7-8,9-10,11,12,13,14,15,16,17,18,19-20$ \\
15 & 0.004 & 0.001 & $1-2,3,4,5-6,7,8,9-10,11,12,13,14,15,16,17,18,19-20$ \\
16 & 0.003 & 0.001 & $1-2,3,4,5-6,7,8,9-10,11,12,13,14,15,16,17,18,19,20$ \\
17 & 0.002 & 0.001 & $1-2,3,4,5-6,7,8,9,10,11,12,13,14,15,16,17,18,19,20$ \\
18 & 0.001 & 0.001 & $1,2,3,4,5-6,7,8,9,10,11,12,13,14,15,16,17,18,19,20$ \\
19 & 0 & 0.001 &
\end{tabular}




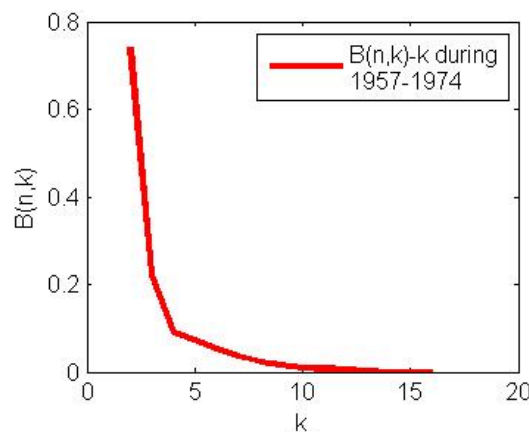

(a)

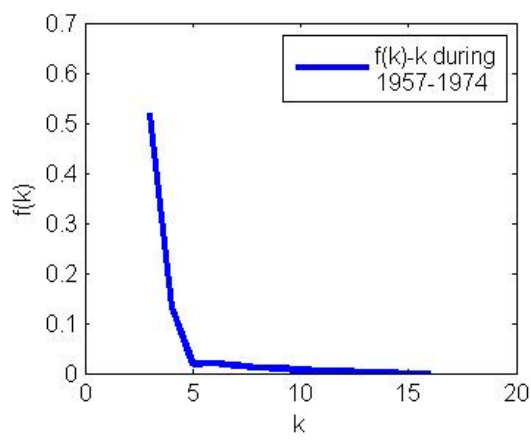

(b)

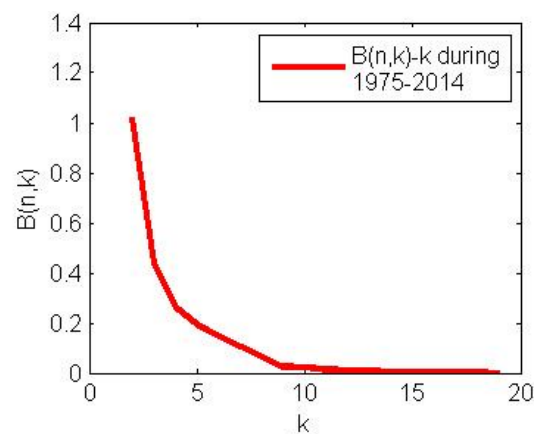

(c)

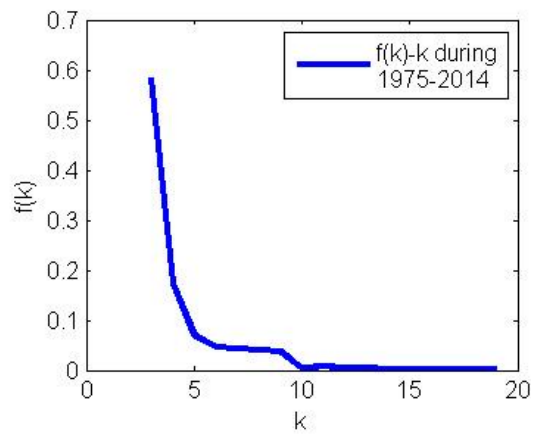

(d)

Figure 5. The $B(n, k)-k$ and $f(k)-k$ curves during 1957-1974 (a,b) and 1975-2014 (c,d).

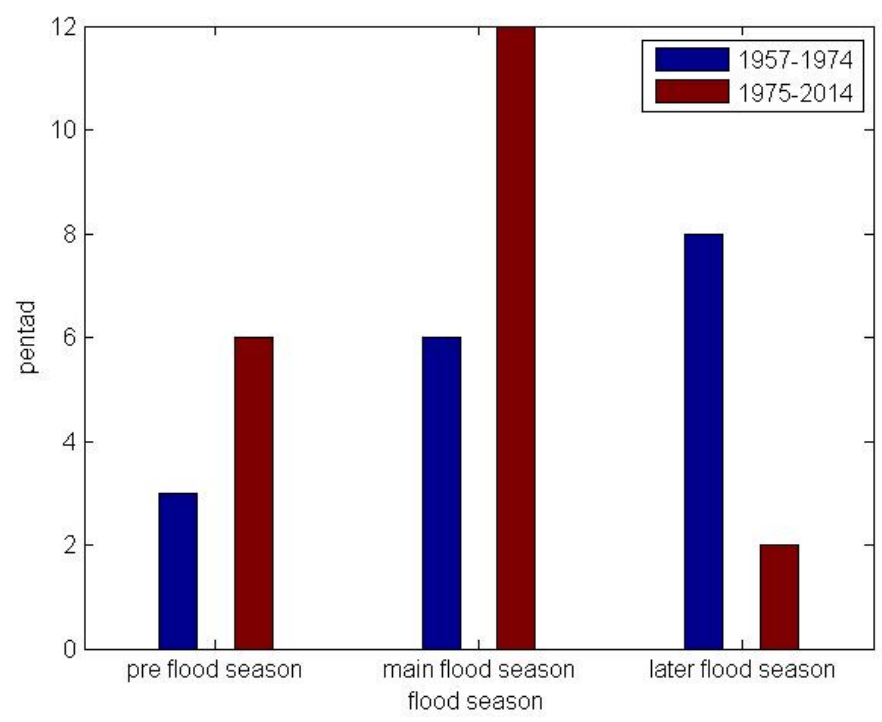

Figure 6. The bar graph of the length of each sub flood season.

\section{Discussion}

This research suggests that the flood season has advanced and extended from climate change since 1974, and it can be divided into three stages. Liu et al. also detected the abrupt point in the Fenhe River Basin, and they found that the precipitation changed abruptly in 1978 [29], which is approximately consistent with the results in this paper. The inconsistency between their article and this paper may derive from the inconsistency of the data-the period studied and the meteorological stations are different, while it is clear that the climate indeed changed significantly in the Fenhe River Basin.

With respect to the onset and retreat time of flood season, according to statistics, the precipitation during flood season account for more than $60 \%$ of the annual precipitation. Thus, the multiscale 
moving $t$-test method is objective and consistent with the characteristics of the precipitation. Pan et al. reconstructed the beginning times of flood season of the middle reaches of Yellow River according to the historical water level data from 1921 to 1950, and the results showed that they range from 6 July to 10 July. Our results indicate that the average onset dates of flood season during the period 1957-1974 and 1975-2014 in the Fenhe River Basin are 19 June and 5 June, respectively, which is inconsistent with Pan's results. Although the Fenhe River Basin lies in the middle reaches of the Yellow River, the terrain here is different from the mainstream of the Yellow River; the Fenhe River Basin is sandwiched between Mt. Lvliang and Mt. Taihang. The method and water level data used in Pan's paper are also different from the moving $t$-test method and the precipitation data used in this paper, which may have caused these differing results.

When it comes to the flood season division, Yang analyzed the diachronic distribution of storm floods and the regularity of flood season division in the Fenhe River Reservoir by recording the number of rainstorm days and the frequency of flood. The results indicated that the flood season can be divided into three stages [30], which is similar to the results of this paper. However, the Fisher optimal partition method focuses on the study from the angle of mathematics; it takes index into consideration more, and the time interval in this paper is 5 days, which is more accurate than 10 days in Yang's paper, so the result of the Fisher optimal partition method is more accurate.

Some countermeasures should be guaranteed to effectively utilize the flood water resources. We often set different flood limit levels during each stage [31]. In general, the prime task during the pre-flood season and the main flood season is flood prevention, so the flood limit levels in the pre- and main flood season should be a little lower. Further, the main purpose during the post-flood season is storing water, so the flood limit level during this period should be a little higher. As the pre-flood season has advanced 15 days and the main flood season has extended by 30 days, the flood limit level during this period should be decreased in advance and sustained longer so that the flood can flow safely through the basin. As for the shortening and delay of the post-flood season, the flood limit level should be elevated later so that flood can be transferred to water resources during this period.

Although some valuable findings have been obtained, further studies are needed to explore the flood season in greater detail. We used daily precipitation only to define the onset and retreat time of the flood season in the Fenhe River Basin. In fact, water level is also relative to the flood season, and the run-off also can impact the flood season. Future research should gather more data and consider more variables. If possible, we can take one reservoir as an example to evaluate the utilizable quantity of flood resources under climate change.

\section{Conclusions}

By using the Mann-Kendall detection, the multiscale moving $t$-test and the Fisher optimal partition methods, we present the onset and retreat dates of each stage in the Fenhe River Basin, which are characterized as the temporal variations from climate change. In the meantime, some useful conclusions of this study can be summarized as follows:

(1) The climate in the Fenhe River Basin has changed since 1974, and the annual precipitation illustrates a downward trend.

(2) The flood season in the Fenhe River Basin during 1975-2014 is 15 days longer than that during 1957-1974. Specifically, the pre-flood season is from 16 June to 30 June during 1957-1974, while it is from 1 June to 30 June during 1975-2014; the main flood season is from 1 July to 31 July during 1957-1974, while it is from 1 July to 31 August during 1975-2014; the post-flood season is from 1 August to 10 September during 1957-1974, whereas it is from 1 September to 10 September during 1975-2014.

(3) The flood limit level should be lowered at an earlier time to resist floods during the pre- and main flood season, and it should be raised at a later time so that more water for utilization can be stored after the flood season. 
Author Contributions: Jianhua Wang contributed to design the methods; Yicheng Wang and Hejia Wang contributed ideas concerning the structure and content of the article; Baodeng Hou and Ya Huang contributed to data collection and processing; Chuiyu Lu drew the figures and maps; Weihua Xiao and Hejia Wang analyzed the results; Hejia Wang wrote the final manuscript.

Conflicts of Interest: The authors declare no conflicts of interest.

\section{References}

1. International Panel of Climate Change (IPCC) Working Group I. IPCC Fifth Assessment Report (AR5); IPCC: Stockholm, Sweden, 23-26 September 2013.

2. Ma, Z.G.; Shao, L.J. Relationship between dry/wet variation and the Pacific Decade Oscillation (PDO) in Northern China during the last 100 years. Chin. J. Atmos Sci. 2006, 30, 464-474.

3. Odekunle, T.O. Determining rainy season onset and retreat over Nigeria from precipitation amount and number of rainy days. Theor. Appl. Climatol. 2006, 83, 193-201. [CrossRef]

4. Sâmia, R.G.; Alan, J.P.C.; Mary, T.K. Revised method to detect the onset and demise dates of the rainy season in the South American Monsoon areas. Theor. Appl. Climatol. 2015. [CrossRef]

5. Hachigonta, S.; Reason, C.J.C.; Tadross, M. An analysis of onset date and rainy season duration over Zambia. Theor. Appl. Climatol. 2008, 91, 229-243. [CrossRef]

6. Ding, J.L.; Xu, Z.S.; Fei, J.F.; Qiang, X.M. Analysis of the definition of the onset and ending dates of the annually first rainy season in South China and its interannual variation characteristics. J. Trop. Meteorol. 2009, 25, 59-65.

7. Gu, R.Y.; Zhou, W.C.; Bai, M.L.; Di, R.Q.; Yang, J. Influence of climate change on ice slush period at Inner Mongolia section of Yellow River. J. Dese. Res. 2012, 32, 1751-1756.

8. Pan, W.; Fei, J.; Man, Z.M.; Zheng, J.Y.; Zhuang, H.Z. The fluctuation of the beginning time of flood season in North China during AD1766-1911. Quatern. Int. 2015, 380, 377-381. [CrossRef]

9. Owusu, K.; Waylen, P.R. The changing rainy season climatology of mid-Ghana. Theor. Appl. Climatol. 2013, 112, 419-430. [CrossRef]

10. Ding, L.L.; Ge, Q.S.; Zheng, J.Y.; Hao, Z.X. Variation of starting date of pre-summer rainy season in South China from 1736 to 2010. Acta. Geogr. Sin. 2014, 24, 845-857.

11. China Meteorological Administration. Available online: http:/ / data.cma.gov.cn/ (accessed on 15 March 2016).

12. Pettitt, A.N. A non-parametric approach to the change-point problem. Appl. Stat. 1979, 28, 126-135. [CrossRef]

13. Wei, F.Y. Modern Climatic Statistical Diagnosis and Prediction Technology; China Meteorological Press: Beijing, China, 1999; pp. 69-72.

14. Fraedrich, K.; Jiang, J.M.; Gerstengarbe, F.W.; Werner, P.C. Multiscale detection of abrupt climate changes: application to River Nile flood levels. Int. J. Climatol. 1997, 17, 1301-1315. [CrossRef]

15. Wang, L.L.; Zou, Y.R.; Sui, H.Q. An objective determination of the beginning and ending date of rainy season in Dalian. Meteorol. Mon. 2000, 26, 12-16.

16. Jiang, J.M.; Fraedrich, K.; Zou, Y.R. A scanning $t$ test of multiscale abrupt changes and its coherence analysis. Chin. J. Geophys. 2001, 44, 31-39.

17. Jiang, J.M.; Mendelssohn, R.; Schwing, F.; Fraedrich, K. Coherency detection of multiscale abrupt changes in historic Nile flood levels. Geophys. Res. Lett. 2002, 29, 112. [CrossRef]

18. Schwing, F.; Jiang, J.M.; Mendelssohn, R. Coherency of multi-scale abrupt changes between the NAO, NPI, and PDO. Geophys. Res. Lett. 2003, 30, 325-348. [CrossRef]

19. Gu, X.Q.; Jiang, J.M. A new application of scanning t-test: Partition of dry/wet episodes in the western USA. Quat. Sci. 2006, 26, 742-751.

20. Liu, P.; Guo, S.L.; Li, W.; Xiong, H.K.; Zhang, W.X.; Guo, H.J.; Xu, D.L.; Wang, Z.X. Application of changing-point method for flood season stage in Geheyan Reservoir. J. Yangtze River. Sci. Res. Inst. 2007, 24, 8-11.

21. Jin, B.M.; Fang, G.H. Application of fuzzy set analysis method on flood stage study of Nanping. Water Power 2010, 36, 20-22.

22. Gao, B.; Liu, K.L.; Wang, Y.T.; Hu, S.Y. Application of system clustering method to dividing flood season of reservoir. Water Resour. Hydropower Eng. 2005, 35, 1-5.

23. Dong, Q.J.; Wang, X.J.; Wang, J.P.; Fu, C. Application of fractal theory in the stage analysis of flood season in Three Gorges Reservoir. Resour. Environ. Yangtze Basin 2007, 16, 400-404. 
24. Xie, F.; Wang, W.S. Set pair analysis and its application to the division of flood period. S-N Water Divers. Water Sci. Technol. 2011, 9, 60-63. [CrossRef]

25. Wang, Z.Z.; Cui, T.T.; Wang, Y.T.; Yu, Z.B. Flood season division with an improved fuzzy c-mean clustering method in the Taihu Lake Basin in China. Procedia Eng. 2012, 28, 66-74. [CrossRef]

26. Wang, Z.Z.; Wang, Y.T.; Wu, H.Y.; Cui, T.T.; Xu, H.; Zhang, Y. Novel flood season division method based on fuzzy time series-effective cluster and its application to Taihu lake basin. J. Hydroelectric Eng. 2012, 31, $29-34$.

27. Chen, L.; Singh, V.P.; Guo, S.L.; Zhou, J.Z.; Zhang, J.H.; Liu, P. An objective method for partitioning the entire flood season into multiple sub-seasons. J. Hydrol. 2015, 528, 621-630. [CrossRef]

28. He, H.W.; Zhang, A.L. The application of Fisher method to dividing seismicity period in Yunnan province. J. Seismol. Res. 1994, 17, 231-239.

29. Liu, Y.F.; Sun, H.; Yuan, Z.H.; Li, Y.R. Time series analysis of precipitation in flood season in fenhe river basin. B. Soil Water Conserv. 2011, 31, 121-125.

30. Yang, H.X. Research on the storm-flood characteristic of basin controlled by fenhe reservoir and its dividing by periods. Shanxi Hydrotech. 2008, 3, 40-41.

31. Gao, B.; Wang, Y.T.; Hu, S.Y. Adjustment and application of the limited level of reservoirs during the flood season. Adv. Water Sci. 2005, 16, 326-333.

(C) 2016 by the authors; licensee MDPI, Basel, Switzerland. This article is an open access article distributed under the terms and conditions of the Creative Commons by Attribution (CC-BY) license (http:/ / creativecommons.org/licenses/by/4.0/). 